\title{
Trust-Building Across Networks Through Festival Organizing
}

\author{
Judeth Oden Choi \\ HCI Institute \\ Carnegie Mellon University \\ jochoi@cs.cmu.edu
}

\author{
James Herbsleb \\ Carnegie Mellon University \\ jim.herbsleb@gmail.com
}

\author{
Jodi Forlizzi \\ HCI Institute \\ Carnegie Mellon University \\ forlizzi@cs.cmu.edu
}

\begin{abstract}
In this case study, we examine how organizers of a grassroots literary and cultural festival built trust across networks in a decentralized curatorial process. Organizers with backgrounds in arts and community organizing used online organizing tactics and tools to connect writers from different neighborhoods, marginalized identity groups and cultural organizations. We observe that the use of social media helped bring openness and transparency to the planning process, inviting broader participation and creating space for social interactions, thus facilitating trust. Brokers played a pivotal role in connecting different networks online and off and fostered collaboration and relationship building. However, in some cases brokering was not enough to establish trust; organizers had to make extra efforts to adapt to groups' cultural and communication norms and make special accommodations to increase inclusivity.
\end{abstract}

\section{CCS CONCEPTS}

- Human-centered Computing; • Human Computer Interaction; $\bullet$ Collaborative and social computing; $\bullet$ Social media;

\section{KEYWORDS}

trust, social media, organizing, networks, festival

ACM Reference Format:

Judeth Oden Choi, James Herbsleb, and Jodi Forlizzi. 2019. Trust-Building Across Networks Through Festival Organizing. In The 9th International Conference on Communities \& Technologies - Transforming Communities (C\&T 2019), June 3-7, 2019, Vienna, Austria. ACM, New York, NY, USA, 6 pages. https://doi.org/10.1145/3328320.3328403

\section{INTRODUCTION}

Using social media, it is easier than ever to form new relationships, maintain existing ones and form social networks. Ad hoc networks on social media organize and activate around shared goals, whether that goal is writing better code, funding a friend's medical treatment or distributing resources during a natural disaster. Social media has played an important role in organizing and executing collective action (e.g. [20] [11] [14]) and fostering community engagement (e.g. [23] [9]).

Permission to make digital or hard copies of all or part of this work for personal or classroom use is granted without fee provided that copies are not made or distributed for profit or commercial advantage and that copies bear this notice and the full citation on the first page. Copyrights for components of this work owned by others than ACM must be honored. Abstracting with credit is permitted. To copy otherwise, or republish, to post on servers or to redistribute to lists, requires prior specific permission and/or a fee. Request permissions from permissions@acm.org.

C\&T 2019, June 3-7, 2019, Vienna, Austria

(C) 2019 Association for Computing Machinery.

ACM ISBN 978-1-4503-7162-9/19/06 ..\$15.00

https://doi.org/10.1145/3328320.3328403
In this case study, we examine the decentralized curatorial processes of a grassroots literary and cultural festival, \#90X90LA. Festivals offer a unique space to celebrate, reflect on a community's values, share resources, and further community development $[3,7,10,17]$. \#90X90LA invited community members to develop festival programming and shape the festival's goals and identity. To achieve this \#90X90LA involved multiple networks of neighborhood residents, artists, writers and cultural organizations. While individuals within each of these networks may be richly connected, connections between networks were weak or nonexistent. Organizing the festival required building connections and a degree of trust across distinct networks. The goals among different networks sometimes conflicted, and were frequently mutually opaque. There were concerns about sharing the spotlight, negotiating group and the festival's collective identities, and appropriation.

While much is known about the role of trust in teams [2] and in online communities [18], less is known about trust in ad hoc networks and how networks join. Through this case study, we gain an understanding of how trust was built across networks, how online tools were used to facilitate trust, and where brokers and additional efforts of inclusion were necessary. We find that online tools helped bring openness and transparency to the organizing process, and brokers played a pivotal role online and off in forging new relationships; however, in some cases, additional efforts were required to build trust among collaborators.

\section{TRUST}

Trust is understood to develop through interpersonal interactions [5]. This has been observed in organizations and among work teams. For example, Wang and Redmiles report that among software development teams informal, non-work talk ("cheap talk") is associated with trust [22].

In online communities, interpersonal interactions are also believed to nurture relationship and trust $[15,18]$. Online, trust has been found to extend to a shared acquaintance (a friend of a friend is a friend) [25]. This has formed the basis for referral systems and networks of trust [13].

\subsection{Trust in Online Organizing}

In traditional organizing, strategic coalition building between organizations and individuals is a central activity [8]. However, online organizing is thought to rely less on relationship-building, and is marked instead by connecting likeminded individuals in ad hoc networks through personal acts of expression; for example, through use of a hashtag [4]. For this reason, online organizing has been criticized for its performativity $[6,16]$ and reliance on weak social ties [12]. 
However, some research suggests that social media provides opportunities for informal social interactions, openness and visibility, which facilitate trust among individuals engaging in collective action [19]. Social media platforms, such as Facebook, provide opportunities for informal social interaction among networks of organizers, activists and community members that helps establish trust [19]. Bennett and Segerberg suggest that social media is the site for building relationships and establishing trust: "These technologies not only create online meeting places and coordinate offline activities, but they also help calibrate relationships by establishing levels of transparency, privacy, security and interpersonal trust" [4].

Other factors that Rohde suggests should be considered when developing ICT for organizing among actors with loose associations, from heterogeneous networks, and in temporary and informal organizing contexts, is visibility and openness and allowing the time required for trust to develop [19].

\section{FESTIVALS}

This case study follows organizers of a grassroots literary and cultural festival who use online organizing tools to bridge networks and build trust. Festivals help bring people together in communities and through shared culture [17]. They provide a temporary space outside of everyday life [21] that focuses on celebration and reflects the values and ideology of a community [7, 10]. Bringing together multiple stakeholders and networks, festivals build and raise awareness around community resources and produces social links between previously unrelated individuals and groups [3].The social capital that is built through relationships and sharing community resources can have lasting effects [3].

Because festivals bring together community members and organizations that may not know each other and may have their own culture, expectations and norms, collaboration can be difficult. Although community members may have high-levels of trust among their own groups and networks, enough trust has to be developed between networks to jointly plan events and develop the identity of the festival.

\section{METHODS}

\#90X90LA was a literary and cultural festival presenting an event every day for 90 consecutive days. Data was collected using participant observation of the design and coordination of the festival and a sample of events, and by coding planning documents and related social media.

\subsection{Setting}

Organizing for \#90X90LA began in January 2017 and extended through the festival which lasted from July 5-October 2, 2017. Approximately half of the events were presented at Cielo Gallery/Studios, an independently owned gallery and community space in South Central Los Angeles. The rest of the events were distributed among community venues and businesses in the Los Angeles neighborhoods of Little Tokyo and Downtown, with a handful of events occurring at other venues around Los Angeles.

Planning meetings occurred over Google Hangout and in-person among the 5 primary organizers in two different states. Facebook, Google Forms, Google Docs, Google Calendar, Instagram, Twitter, email, text message and a festival website (90x90la.com) were all used for coordination and communication between participants and the organizers.

\subsection{Data}

One of the authors was a festival organizer. In the role of festival organizer, she brought her knowledge of collective action online to the design of the \#90X90LA's decentralized curating processes. With the knowledge of her fellow organizers, she employed participant observation, taking field notes of the festival development and coordination process and five weeks of daily events. One author coded planning documents (e.g. internal operating policies, mission statements, volunteer and proposal forms) for evidence of program design decisions, division of tasks and responsibilities, and communication between organizers, participants, and brokers. Facebook posts related to \#90X90LA from the organizers' public accounts, and 87 Facebook event pages created for separate events were also coded for types of social interaction, event planning and logistics, and brokering. We kept a record of roles and tasks for organizers, volunteer curators, volunteer support positions, performers and brokers. In addition, we scraped tweets related to \#90X90LA from July 6- July 25, 2017 and August 8 - October 10, 2017 and coded these according to the role of the tweeter in the festival and the tweet content (e.g. a call for participation, advertising an event, or reporting about an event).

\section{THE CASE: \#90X90LA}

\#90X90LA was created by Writ Large Press, an independent publisher in Los Angeles. Events included readings, performances, art exhibits, panel discussions, dance parties and workshops. Events were curated and produced by local community members and featured the writing, music and art of people from marginalized communities, independent publishers and local literary, cultural and activist organizations.

\subsection{History}

The first iteration of the 90 day literary and cultural festival ran in the summer of 2014 as a pop-up series in a bar within Union Station, the main train station in Downtown Los Angeles. The festival created a space to feature the diversity of talent within the Los Angeles literary community. Over the course of the summer of 2014, it became clear that the real value of the festival was its ability to hold space and shine a spotlight on writers from marginalized identities, bringing them to the forefront of the Los Angeles cultural scene.

\subsection{Festival Design}

In 2017, Writ Large Press sought to expand the goals and scope of the festival. They set out to design a festival that would connect writers across cultural and geographical boundaries (geography being a significant obstacle in the sprawling city of Los Angeles), center writers from marginalized groups-especially those from the neighborhoods in which the festival took place-and help reduce the socio-spatial distance between marginalized groups and the city's literary and cultural institutions. 
The three partners of Writ Large Press reached out to two additional community organizers, both of whom were deeply embedded in their local communities-one located in South Central and the other in Little Tokyo. This team of 5 were the primary organizers of the festival.

The team adopted an organizing model that was influenced by community organizing techniques and online collective action. This included using social media tools, such as a festival hashtag, posting calls to action on social media sites, and creating Facebook event pages. The name of the festival was its hashtag, \#90X90LA. The organizers intentionally chose a festival name that did not include any group identity or communicate the organizer's values. Instead the name was a blank slate, allowing room for participants to personalize and shape it through their participation.

\subsection{Decentralized Event Coordination}

In conventional festival planning, a team of organizers curate and produce performances, hire vendors and plan activities for the public. In \#90X90LA, the public was invited to curate the festival and organizers played the role of facilitator, helping participants develop events and connecting them to presenters, venues and other resources as needed.

Spanning 90 days, festival events were being developed and scheduled during and up until the last week of the festival. This allowed participants to shape the content and the identity of the festival as it unfolded. To provide some structure and an overall narrative arc to the festival, the organizers scheduled the opening and closing weeks of events as an introduction and closing/debrief. They also scheduled symposium weekends, grouping together a series of related panels, performances and discussions around a theme. Curated by community members and organizers, symposium themes included anti-gentrification, the immigrant experience, disability and access, and interactive narratives.

\section{BUILDING TRUST}

In total, \#90X90LA 2017 incorporated 55 organizations, businesses and groups, and over 260 presenters and volunteers with events in 17 different venues. With the stated goal of connecting groups of artists and writers, encouraging new collaborations, and developing a festival community and identity, it was essential that the festival organizers facilitated trust between participants and with organizers. This was accomplished through openness and transparency, with the help of brokers, and by exerting effort to ensure inclusivity.

We observed trusting behaviors in participants' social interactions on social media, their willingness to collaborate with unknown parties (with the help of brokers and through the efforts of organizers), their ability to follow through on event planning tasks, and evidence of ongoing collaborations.

\subsection{Openness and Transparency}

The organizers made efforts both online and off to open up the process and invite participants to take part in festival production. Posting about the process online allowed space for social interactions, including off-topic discussion and joking, while open calls for participation created avenues for people without social ties to the organizers to participate. During offline events and through personal interactions, organizers set expectations and opened strategic planning and coordination discussions to the public.

Starting in January of 2017, the organizers published a series of 8 articles on a multi-author blog about the festival and organizing process. These articles helped articulate the values of the festival and discuss its community-centered structure and decentralized curatorial processes. In addition to these 8 articles, the organizers posted approximately 16 posts on Facebook (some re-posted to Instagram and Twitter) before the festival began. In the comment threads to these Facebook posts participants expressed enthusiasm, volunteered and joked around. For example, the announcement of \#90X90LA generated 61 comments and 18 shares. Among the comments, 29 were expressions of enthusiasm (e.g. "Yes! I'm in!") and 10 were offers of resources and discussions of particular event proposals and dates. In a series of posts, a Writ Large Press collaborator (but not a festival organizer) created humorous memes riffing off of the hashtag. These opportunities for both on-topic and off-topic social interactions leading up to the festival helped establish relationships and made existing relationships between participants and organizers publicly visible.

Two calls for participation via Google Forms were circulated on social media a month before the festival. One was a call for event proposals, and the second was a call for volunteers to fill support roles. 34 of the 101 respondents participated in the festival, and 28 proposals developed into unique events. 13 of those participants had no prior collaborations with any of the organizers. Respondents were kept informed on the organizing process via group and personal emails, which set expectations of transparency on the part of organizers and made clear the uniquely participatory nature of the festival's coordination and curation.

Organizers opened strategic goal-setting and identity formation processes to the public before, during and at the close of the festival. This included educating the public about the needs of neighborhood and community stakeholders, contextualizing the festival alongside other community organizing efforts, and hosting strategy discussions and planning workshops. Included in the first week of events were opening receptions, performances, and talks intended to center the local neighborhoods and welcome festival participants from outside of the community. This served as a gesture of good faith to community collaborators, assuring that their needs and values were a priority and also educated newcomers. For example, community leaders in Little Tokyo held a welcome event that included live performances from community elders, a documentary on the history of the neighborhood and a presentation by local politicians on the challenges Little Tokyo currently faces. Organizers also created opportunities to publicly negotiate participants' goals and gain participant buy-in. At one event during the opening week, participants generated a list of goals and intentions for \#90X90LA through facilitated discussion. Organizers also held workshops to help community members develop their event or project ideas and connect with potential collaborators.

\subsection{Brokers}

Throughout the festival coordination process, individuals took on the role of broker, connecting festival organizers and participants 
to individuals and groups outside of their network. Brokers proved important in connecting networks and building the trust necessary for collaborators to discover and act on their shared goals. We observed three types of brokering roles: organizers serving as brokers to groups of which they were a member, organizers brokering relationships between participants, and participants who brokered new relationships between organizers and other individuals or groups outside of the organizers' networks.

6.2.1 Organizers as brokers to groups. Each organizer had access to communities or organizations that the other four did not. The organizer with the existing relationship was trusted to negotiate and manage event coordination with these groups and decide when it was appropriate to include others. For example, one organizer has worked for over twenty years as a music producer and promoter. Having a reputation for finding innovative talent and producing quality shows, he was able to book top, local musicians and offer his personal assurance that events would be well-produced and artistically relevant to them. Likewise, the other organizers trusted his ability to match musicians to an event appropriately. The organizer's communication with musicians was often one-on-one via direct message, phone and in-person conversations that did not involve the other four organizers.

Another organizer is a member of a local radical collective. This collective was initially hesitant to participate in the festival because they were concerned about privacy and safety issues and their ability to accurately present themselves and their values within the festival context. To broker trust with the collective, the organizer took steps to ensure that the collective's social/political message would not be watered down or appropriated by the festival. She encouraged them to host their own Facebook event pages (without the festival organizers as co-hosts) and helped them create events that were intentionally POC (People of Color)-Queer/Trans-only spaces. To ease tensions, the organizer with membership handled all communication and negotiations with the group, only filling in the other organizers when an event had been planned and was added to the Google Calendar.

6.2.2 Organizers brokering between participants. In some cases, organizers served as brokers between participants, encouraging new collaborations when there was not a pre-existing relationship. For example, in the call for proposals, one participant wrote that she wanted to curate an event about "writing the immigrant experience." Based on this proposal the organizers developed a weekend symposium around the theme "the immigrant experience." The participant who originally proposed the event wanted to develop a writing workshop and discussion for U.S. immigrants. In order to increase the participants' access to immigrants from different parts of the world, the organizers suggested she partner with someone who expressed interest in the Google Form in organizing an Asian and Pacific Islander centered event. An organizer emailed each participant separately about the idea, and once she had the participants' approval introduced them on an email chain. The organizer checked in with the participants periodically for updates on event planning.

6.2.3 Participants as brokers. Participants also served as brokers, connecting organizers to new participants, organizations and venues.
We counted 28 instances when participants served as brokers for an event. In some cases, a simple introduction might be enough to spur a new relationship. For example, when developing a panel discussion with POC art critics, one of the organizers put out a call for participants on Facebook and other people tagged in those who fit that description from their own networks. In another case, an organizer wanted to invite an activist group for a community discussion on "artwashing" (the use of art and art galleries to "clean up" a neighborhood undergoing redevelopment) and actions artists can take in anti-gentrification efforts. The organizer reached out to a colleague who was associated with the activist group. The colleague acted as a broker, connecting with key members of the activist group and introducing everyone via email. However, the activists had to decide amongst themselves how they wanted to participate, and whether participation would make themselves and the festival a target of backlash from their detractors. The broker was pivotal in backchannel conversations, vouching for the organizers and festival and offering to serve as a discussion facilitator. While these discussion were happening behind-the-scenes, the organizer had to contact the broker for updates on the activists and their concerns. To help prepare attendees for the discussion and to demonstrate that the festival organizers and activist group shared political views on the topic, the broker posted relevant articles on the Facebook event page and engaged commenters with opposing views.

Participants also contacted the organizers to broker the use of venues and connect organizers to new participants and organizations. For example, seeing festival posts on social media, an out-ofstate colleague Facebook messaged one of the organizers in April and suggested he invite a Los Angeles-based filmmaker with a new documentary on the 1992 Los Angeles Uprising to participate. Taking an active role in brokering, she then emailed the filmmaker and organizer putting them in touch. Later, when looking for a venue to screen the documentary and host a talkback with the filmmaker, the broker contacted an associate of hers who owns a restaurant in Koreatown and booked the venue. The social brokering, however, did not stop there. The Director of Programming at Grand Performances, a free outdoor concert series in Downtown Los Angeles, contacted one of the organizers (initially through a Facebook comment thread) asking him to curate a \#90X90LA event in commemoration of the 25th anniversary of the uprising as part of the concert series. The organizer was able to include the filmmaker and excerpts of her film in the event and in front of a broad audience.

\subsection{Effort and Inclusivity}

Although brokers were essential to forging new collaborations and bridging existing networks, sometimes their efforts were not enough to inspire trust between participants and organizers. In these cases, organizers had to demonstrate their willingness to prioritize the needs and adjust to the norms of each participant, including their communication media preferences and accessibility needs. This communicated that the festival centered its participants, was invested in developing a supportive and inclusive festival community, and was interested in building mutually respectful relationships that could extend beyond the festival. 
6.3.1 Media Choice. Media choice theory suggests that when faced with multiple communication options, individuals and organizations develop norms over time based on a number of factors, including organizational structure, the nature of the task, and interpersonal trust [24]. Organizers adjusted to the media choices and communication norms established by their collaborators. Doing so made it easier to sustain interpersonal interactions and build trust.

Some organizations had more formal bureaucratic structures and processes in place to reach consensus among collaborators and stakeholders. Engaging these more formal structures required extra work for the organizers, but resulted in increased trust. For example, in order to build a relationship with a network of Little Tokyo organizations, organizers attended 7 in-person meetings prior to the festival. Presentation was very important to this group, and long email conversations, often including representatives from three or more organizations, persisted about what image to use on Facebook event pages, how to properly credit the curators and sponsors, and the writing of event descriptions.

In order to maintain communication with other participants, organizers went out of their way to meet participant's schedules and adjust to their communication preferences. Sometimes this meant an organizer would stop by a participant's place of work (e.g. during a bar tending shift) or, for example, meet with musicians late at night, after a gig. Organizers also adhered to an individual's media choices. For example, if a participant was known to "always be on Instagram," then organizers would message them via Instagram.

6.3.2 Inclusivity. Particular events were geared toward children, older adults, non-English speakers and persons with disabilities. These events required specific accommodations, such as providing interpreters, moving events to venues with greater accessibility and providing options for participants to participate remotely. This was particularly important for a panel discussion on disability and access, which was held in an accessible venue and video conferencing was arranged for two panelists with disabilities to participate remotely. Organizers and participants had to negotiate each of these needs given limited time and budget. This extra effort and additional communication became the basis for establishing relationships and trust.

\section{CHALLENGES}

In order to organize a decentralized festival in a networked environment, multiple social media platforms and other ICTs were used. Engaging an ecology of communication tools allowed organizers to match the communication needs and expectations of the participants and to build trust through transparency, social interaction and brokering. However, this also created challenges for organizers who had limited awareness of each other's actions and had to manage a number of different communication channels at once.

We observe that different tools were used for different types of communication. For example, Facebook comment threads were often the site of informal interactions, volunteering, and brokering. Nearly every event (91 of 93) had their own Facebook event page where users publicly signaled their intent to attend events. Twitter, on the other hand, was primarily used as a marketing tool, sharing event announcements, including links to the festival web page and Facebook event pages, and mainstream media coverage of the festival. The tweet corpus includes only a few instances of on-topic or off-topic discussion about the festival or its coordination. Although we do not have a complete record of emails and direct messages involving organizers, from our field notes we observe that the more centrally organized non-profit organizations preferred email communication, while individual participants often appreciated synchronous communication via direct messaging apps.

However, using an ecology of tools to coordinate a festival in a decentralized process also presented challenges for the organizers. With so many avenues for communication, organizers were often unaware of the actions of each other (in cases where trust had to be carefully brokered with participants, this was intentionally so). Occasionally events were scheduled over each other and communication with participants was either duplicated or dropped, which was potentially damaging to the relationships organizers were attempting to build. Despite using collaborative work tools, such as Google Calendar and Sheets, one of the organizers became the clearinghouse for information and coordination for the other four organizers. This significantly increased his workload.

\section{ONGOING COLLABORATIONS}

Many relationships formed during \#90X90LA in the summer of 2017 persist today and have led to new collaborations. This is evidence that trust established during the festival helped join networks beyond the 90 days. For example, two participants who volunteered in support positions for a recurring reading series during \#90X90LA, decided to continue producing the event in collaboration with Writ Large Press once the festival was over. It has been running now for two years. Another two participants who met during \#90X90LA, one a visual artist and the other a poet, were awarded a grant to teach a series of art and writing workshops at local libraries and archive the stories and art created in the workshops using the Japanese tradition of Kamishibai. Relationships between local businesses and writers have also been ongoing. A venue that had not hosted literary events before \#90X90LA now regularly hosts readings and book launch events for local authors. Anecdotally, we also observe writers reading together at local literary events who had no relationship prior to \#90X90LA, suggesting that their professional networks now overlap.

\section{DISCUSSION}

While \#90X90LA used online tools and tactics similar to other online collective actions, such as hashtag campaigns and Facebook event pages, \#90X90LA differed from these efforts in their need to establish trust in order to link distinct networks, collaborate on shared tasks, and negotiate the identity and goals of the grassroots festival. Community-driven festivals like \#90X90LA may also serve to establish relationships and trust that extends beyond the festival to future collaborations, community engagement and collective action.

Similar to prior research on trust in teams and in online communities, interpersonal interaction was key to establishing trust. Social media, especially Facebook comment threads, provided a site for social interaction around event coordination. However, this was not sufficient to build trust between networks and amongst groups with 
either opaque or conflicting values and goals. Personal relationship building often required one-on-one interactions via email, phone or direct messages, and sometimes in-person meetings. Brokers played a pivotal role in facilitating relationships across networks; however, sometimes organizers had to demonstrate extra effort and commitment in new relationships by adapting to participants' needs and communication norms.

The use of online tools allowed organizers to be open about the coordination process and invite broad participation. Having multiple avenues for communication and coordination helped organizers adapt to the needs and communication norms of diverse participants. While essential to building trust, this personalized approach to coordination in a decentralized process created a lack of awareness and opportunities for miscommunication among the organizers. This led to the development of alternate coordination strategies (i.e. one organizer becoming the hub of many collaborations) and possibly corroded trust with community partners.

Festivals are sites for community development and increasingly, through efforts like SXSW's Social and Global Impact Tract [1], activism. Decentralized festival curation processes provide communities the opportunity to reflect on their own values and cultures, share resources, and develop relationships. Grassroot festivals play a role in building trust across diverse groups and networks; we have noted some examples of new and ongoing collaborations that grew out of \#90X90LA. On a larger scale, the trust built between individuals and groups may also facilitate future community engagement and collective action.

\section{CONCLUSION}

We present this case study of a grassroots festival organized through decentralized curatorial processes using online tools as an exploration of how trust is built across networks in a festival context. The organizers used social media to bring openness and transparency to the coordination process, invite broad participation, and support social interaction. Brokers, acting both online and offline, were essential in forging new relationships and building trust, and sometimes organizers exerted extra effort to meet participants' needs and conform to communication norms.

\section{ACKNOWLEDGMENTS}

Thank you to Jessica Hammer for her support of this research. Thank you to Chiwan Choi, Peter Woods, traci kato-kiriyama, Skira Martinez, Kate Maruyama, Rocìo Carlos, Ana Chaidez, Cielo Galleries/Studios, Little Tokyo Service Center, Little Tokyo communities, South Central communities, and the entirety of the Los Angeles literary community.

\section{REFERENCES}

[1] 2019. Social Global Impact $\mid$ SXSW Conference Festivals. Retrieved April, 25, 2019 from https://www.sxsw.com/conference/social-and-global-impact/

[2] Ban Al-Ani and David Redmiles. 2009. Trust in distributed teams: Support through continuous coordination. IEEE software 26, 6 (2009), 35-40.

[3] Charles Arcodia and Michelle Whitford. 2007. Festival attendance and the development of social capital. In fournal of Convention \& Event Tourism, Vol. 8. Taylor \& Francis, 1-18.

[4] W. Lance Bennett and Alexandra Segerberg. 2012. The logic of connective action. Digital media and the personalisation of contentious politics. Information, Communication \& Society 15, 5 (2012), 739-768. https://doi.org/10.1080/1369118X. 2012.670661
[5] Dorwin Ed Cartwright and Alvin Ed Zander. 1960. Group dynamics: Research and theory. (1960).

[6] Henrik Serup Christensen. 2011. Political activities on the Internet: Slacktivism or political participation by other means? First Monday 16, 2 (2011).

[7] Gerard Delanty, Liana Giorgi, and Monica Sassatelli. 2011. Urban festivals and the cultural public sphere: Cosmopolitanism between ethics and aesthetics. In Festivals and the cultural public sphere. Routledge, 24-40.

[8] Mario Diani and Ann Mische. 2015. Network approaches and social movements. The Oxford handbook of social movements (2015), 306-325.

[9] Sheena L Erete. 2015. Engaging around neighborhood issues: How online communication affects offline behavior. In Proceedings of the 18th ACM Conference on Computer Supported Cooperative Work \& Social Computing. ACM, 1590-1601.

[10] Alessandro Falassi. 1987. Festival: Definition and morphology. Time out of Time: Essays on the Festival (1987), 1-10.

[11] Deen Freelon, Charlton Mcllwain, and Meredith Clark. 2018. Quantifying the power and consequences of social media protest. New Media \& Society 20, 3 (2018), 990-1011.

[12] Malcolm Gladwell. 2010. Small Change. The New Yorker (2010).

[13] Audun Jøsang and Touhid Bhuiyan. 2008. Optimal trust network analysis with subjective logic. In 2008 Second International Conference on Emerging Security Information, Systems and Technologies. IEEE, 179-184.

[14] Hanlin Li, Disha Bora, Sagar Salvi, and Erin Brady. 2018. Slacktivists or Activists?: Identity Work in the Virtual Disability March. In Proceedings of the 2018 CHI Conference on Human Factors in Computing Systems. ACM, 225.

[15] Katelyn YA McKenna, Amie S Green, and Marci EJ Gleason. 2002. Relationship formation on the Internet: WhatâĂŹs the big attraction? fournal of social issues 58, 1 (2002), 9-31.

[16] Joel Penney. 2015. Social media and symbolic action: Exploring participation in the facebook red equal sign profile picture campaign. Fournal of ComputerMediated Communication (2015). https://doi.org/10.1111/jcc4.12092

[17] Albert Piette. 1992. Play, reality, and fiction: toward a theoretical and methodological approach to the festival framework. Qualitative Sociology 15, 1 (1992), 37-52.

[18] Yuqing Ren, F Maxwell Harper, Sara Drenner, Loren Terveen, Sara Kiesler, John Riedl, and Robert E Kraut. 2012. Building member attachment in online communities: Applying theories of group identity and interpersonal bonds. Mis Quarterly (2012), 841-864.

[19] Markus Rohde. 2013. Trust in Electronically-Supported Networks of Political Activists. In Workshop Paper, Proceedings of ACM Conference on Computer Supported Cooperative Work.

[20] Zeynep Tufekci. 2017. Twitter and tear gas: The power and fragility of networked protest. Yale University Press.

[21] Victor Witter Turner and Richard Schechner. 1988. The anthropology of performance. (1988).

[22] Yi Wang and David Redmiles. 2016. Cheap talk, cooperation, and trust in global software engineering. Empirical Software Engineering 21, 6 (2016), 2233-2267.

[23] Anne Marie Warren, Ainin Sulaiman, and Noor Ismawati Jaafar. 2014. Social media effects on fostering online civic engagement and building citizen trust and trust in institutions. Government Information Quarterly 31, 2 (2014), 291-301.

[24] Mary Beth Watson-Manheim and France Bélanger. 2007. Communication media repertoires: Dealing with the multiplicity of media choices. MIS quarterly (2007), 267-293.

[25] Masaki Yuki. 2003. Intergroup comparison versus intragroup relationships: A cross-cultural examination of social identity theory in North American and East Asian cultural contexts. Social Psychology Quarterly 66, 2 (2003), 166-183. 